\title{
Arbor
}

\section{Madrid en 1900: La capital del sistema educativo}

Estíbaliz Ruiz de Azúa Martínez de Ezquerecocha

Arbor CLXIX, 666 (Junio 2001), 519-539 pp.

\section{Introducción: La atracción de Madrid en el mundo académico}

En abril de 1892, después de unos ejercicios de oposición que duraron varios meses, llegó a Madrid Santiago Ramón y Cajal (1852-1934) para ocupar la cátedra de Histología normal y Anatomía patológica que había dejado vacante el fallecimiento del doctor Aureliano Maestre de San Juan. Llegar a la Universidad Central era en aquel tiempo el ideal de todo catedrático de provincias. Ramón y Cajal había ganado en 1883 la cátedra de Anatomía de la Universidad de Valencia, y de allí pasó a la Universidad de Barcelona, a cuyo claustro perteneció durante cerca de cinco años. Con «verdadera pena -escribirá más adelante - hube de abandonar a tan excelentes amigos y con ellos a una ciudad donde encontré ambiente singularmente favorable para la ejecución y publicación de mis trabajos científicos»; en la ciudad condal pasó también «ratos inolvidables» gracias a la tertulia de la Pajarera de la que eran asiduos, entre otros, algunos profesores universitarios que en breve harían el mismo traslado a la capital del Estado, como García de la Cruz, el cubano Villafañé, y Castro Pulido. Para Ramón y Cajal, ser catedrático de la Central «coṇstituía entonces la única esperanza de satisfacer con cierta holgura mis aficiones hacia la investigación y de aumentar mis recursos». Madrid ofrecía, en efecto, a sus profesores un plus nada desdeñable en concepto de residencia, así como la industria del libro de texto y los derechos de examen, cosas ambas que resultaban tan lucrativas en la Villa y Corte como precarias en provincias. Además, Madrid era la residencia habitual 
de los principales capitalistas del Estado, clientela potencial de abogados, médicos y farmacéuticos, y particularmente de los catedráticos universitarios, que por ostentar ese título ya eran reconocidos como los profesionales más sabios de la ciudad, y así era frecuente que estos profesores compaginaran la actividad docente con el ejercicio social de su profesión. En el caso de Ramón y Cajal, sin embargo, sólo en la «decorosa industria del libro de texto» entreveía él «el aurea mediocritas» capaz de garantizarle «el bien supremo de la independencia de espíritu» 1 .

Pero Madrid significaba mucho más que privilegios económicos. Era la capital del Estado y, por serlo, era también la capital de un sistema educativo que, diseñado en la Ley de Instrucción Pública (Ley Moyano) de 1857 con criterios centralistas, gravitaba sobre las instituciones instaladas en la Villa y Corte. Madrid era la sede de ka Universidad Central, y sólo en ella se cursaban a comienzos del siglo XX casi todas las carreras y todas las secciones de las licenciaturas oficiales del Estado, y el doctorado, por lo que se hacía necesario estudiar en la capital si se aspiraba a una determinada titulación o a culminar la carrera con el grado de doctor. Esa exclusiva académica era sin duda una de las razones de la atracción centrípeta que ejerció la capital sobre alumnos y profesores en aquel tiempo, pero también la causa de que se cortara en las demás Universidades «toda posibilidad de mantener grupos de trabajo investigador» ${ }^{2}$. Los centros educativos de la capital (Institutos, Escuela Normal, de Artes y Oficios, de Comercio, etc., además de la Universidad) se clasificaron de primera categoría, tras de los cuales venían ordenados los restantes del país. Las oposiciones para ingresar en el Profesorado se celebraron siempre en Madrid, no alterándose la norma hasta 1900 y sólo en los casos de provisión de escuelas elementales y superiores en la enseñanza primaria ${ }^{3}$.

En Madrid estaban además las sedes de las Academias, las sociedades científicas, financieras, periodísticas y culturales de mayor proyección en el país, los Ministerios, el Parlamento y las agrupaciones políticas que tejían precisamente desde la capital sus poderosas redes clientelares ${ }^{4}$. Por todo ello, el catedrático que ejercía en la capital del Estado tenía abiertas posibilidades de trascender la función docente, y de alcanzar una representación social y política en mayor medida que los restantes profesores de provincias ${ }^{5}$. Así, por poner algunos ejemplos, el Consejo de Instrucción Pública se reorganizó nada más crearse el nuevo Ministerio de Instrucción Pública y Bellas Artes en 1900, llevando a formar parte del mismo, según dejó escrito el primer titular de la cartera, García Alix, «lo más notable del Profesorado 
residente en Madrid» ${ }^{6}$; la representación corporativa en el Senado de cinco de las diez Universidades entonces existentes recayó en 1900 en otros tantos catedráticos de la Central, y en la plantilla madrileña del personal docente de aquel mismo año figuraron tres profesores que habían sido Ministros durante el Sexenio y ocho que lo serán a partir de 1900, amén de otros, que sin llegar a serlo, hicieron una brillante carrera política, como parlamentarios, subsecretarios, directores generales, etc ${ }^{7}$. Finalmente, en el ámbito puramente educativo y científico, Madrid fue el escenario de las dos iniciativas más prestigiosas que se dieron durante la Restauración: la Institución Libre de Enseñanza (1876) y la Junta de Ampliación de Estudios (1907). Por este motivo, no tenía nada de sorprendente que entre el profesorado del claustro madrileño se contaran bastantes nombres vinculados con la I.L.E., y que casi todos los miembros de la primera Junta directiva de la J.A.E. pertenecieran al citado claustro. Hacia 1900 precisamente Giner de los Ríos cambió la estrategia que había seguido hasta entonces de difundir la Institución por provincias, por la de concentrar en la capital del Estado las minorías selectas afines al espíritu institucionista, produciéndose así en los años inmediatos la llegada a la Universidad Central de eminentes figuras ligadas a la Institución ${ }^{8}$.

El propósito de este trabajo es mostrar la situación escolar (enseñanza primaria, secundaria y universitaria) existente en Madrid en 1900, y verificar la validez del supuesto de partida: que la Universidad Central resultó ser, como la Villa y Corte que le servía de asiento, una Universidad de aluvión, a la que concurrieron alumnos y profesores de todos los rincones del Estado para cursar unos estudios o para continuar una tarea docente que en la mayoría de los casos se había iniciado en provincias. El padrón municipal, por otra parte, permitirá adentrarnos en el ámbito social y conocer, en su caso, las formas de instalación en la villa madrileña de los catedráticos de su claustro ${ }^{9}$.

\section{La enseñanza primaria: un nivel abandonado desde el poder a la iniciativa privada}

Madrid era a comienzos del siglo XX una ciudad que carecía de plazas docentes en la enseñanza primaria. La población en edad escolar, según el censo de 1900, daba un total de 62.057 niños-as de edades comprendidas entre seis y doce años de edad, mientras que la oferta de plazas fue sólo de 40.160 (12.960 en los establecimientos públicos y 27.200 en los privados), de modo que algo más de la tercera parte 
de esa población (21.897) no podía materialmente acceder a un puesto escolar en los establecimientos (públicos o privados) de la ciudad. En 1918 , ese porcentaje había bajado a la mitad ${ }^{10}$. Con todo, la matrícula operada realmente en esos años no llegó a agotar las plazas teóricas ofrecidas: en 1900 se han calculado unos 11.600 alumnos-as en las escuelas públicas (18,7 por 100 de la población en edad escolar) y 27.200 alumnos-as en la enseñanza privada (43,8 por 100), y en 1918 la situación sería aproximadamente de unos 18.786 alumnos-as en la escuela pública (23,4 por 100 de la población en edad escolar) y 39.430 alumnos-as en la privada (49,2 por 100), siendo las plazas teóricas en este último año 66.244 (22.586 públicas y 43.658 privadas) ${ }^{11}$. En cualquier caso, dos observaciones parecen desprenderse de las cifras expuestas: primera, el porcentaje elevado de niños-as sin escolarizar (37,5 por 100 en $1900,27,4$ por 100 en 1918), porcentaje que, sin embargo, era inferior al del conjunto nacional (41,5 por 100 en 1908); y segunda, el predominio de la escuela privada en la enseñanza primaria madrileña. Frente a las 144 escuelas públicas primarias existentes en 1900 (72 de niños, 71 de niñas y 1 de patronato; 25 superiores y 118 elementales) se contaban 368 escuelas privadas ${ }^{12}$.

El Ayuntamiento de Madrid (del que dependió económicamente, como en el resto de los municipios españoles, la enseñanza primaria hasta 1900-1902) no se esforzó en exceso por cumplir las exigencias de la Ley Moyano, razón por la cual en la capital hubo siempre menos escuelas públicas que las necesarias. Esa circunstancia no fue, sin embargo, privativa de Madrid, sino bastante común a comienzos del siglo $\mathrm{XX}$, sobre todo en las grandes capitales, como Barcelona, Valencia, Cádiz, Sevilla, Zaragoza y Murcia, donde las escuelas privadas suplían en muchas ocasiones a las públicas ${ }^{13}$. Si en el conjunto del Estado la oferta pública era, en este nivel de enseñanza, la dominante con gran diferencia (entre otras cosas, porque no había otra en la inmensa España rural), lo contrario sucedía en los grandes núcleos urbanos, donde residían habitualmente familias de clases medias/altas que requerían para sus hijos una educación más esmerada que la que se impartía en la escuela pública. Ésta quedó reservada en las ciudades prácticamente a las clases populares y, en el caso de Madrid, al menos, ni siquiera a la totalidad de aquéllas por la baja tasa de cobertura que la escuela pública tuvo, como se ha dicho, en esos años. En consecuencia, Madrid era también uno de los municipios que menos gastaba proporcionalmente en educación ${ }^{14}$, dedicando a esta función únicamente el 4 por 100 del gasto municipal total.

El desglose de aquel gasto evidenciaba las diferencias que entonces existían entre la capital del Estado y las capitales de provincias, por 
lo menos, en dos conceptos: 1) el gasto en personal (un maestro en Madrid cobraba 2.750/3.000 pesetas al año, según fuera de escuela elemental o superior, lo que les convertía en los maestros mejor pagados del país con sensible diferencia); y 2) el gasto en transferencias (aquéllas que en los presupuestos de provincias aparecían destinadas al Instituto de segunda enseñanza, a la Escuela Normal, de Artes Oficios, de Comercio, etc., eran transferencias que el Ayuntamiento madrileño se ahorraba al estar financiadas esas instituciones prácticamente por el Estado, si bien en Madrid se subvencionaba con fondos municipales a los colegios de San Fernando y de San Antonio Abad, y a la Asociación para la enseñanza de la mujer). En el Ayuntamiento de Madrid, durante los años 1886-1892, el gasto en personal representó el 60,1 por 100 del gasto municipal total en educación, las transferencias el 3 por 100, el material de las escuelas el 9,1 por 100, el alquiler de los locales el 26,1 por 100 , y el 1,7 por 100 restante se dedicó a inversiones ${ }^{15}$.

La mayoría de las escuelas públicas (en menor proporción las privadas) estaban ubicadas en locales alquilados, lo que, aparte de constituir un campo de influencias y favores entre los gestores municipales de la enseñanza y los propietarios de las casas, suponía un gasto enorme para el Ayuntamiento, y limitaba considerablemente la eficacia de la práctica educativa al ser lugares (pisos de los inmuebles, en muchas ocasiones) nada adecuados para esa finalidad. Su distribución por la ciudad presentaba asimismo anomalías destacadas: mientras los distritos de Centro y Congreso contaban con las escuelas necesarias, en todos los demás había falta de centros públicos, pero era en el distrito popular de Inclusa y en Hospital donde el problema resultaba más acuciante porque en ellos también escasearon las escuelas privadas ${ }^{16}$. Se trataba, por otra parte, de escuelas unitarias (las graduadas empezaron a funcionar en Madrid a partir de 1903), cuya dotación de enseres era harto insatisfactoria. «Malos, malísimos son la mayoría de los locales —confesó el delegado regio de Madrid Ruiz Jiménez (cargo restaurado en 1902 para mejorar la enseñanza pública en las grandes capitales)—; pero el material fijo, excepciones muy contadas, es aún peor, existiendo mucho que cuenta veinticinco y treinta años de uso» ${ }^{17}$. Así, la situación pedagógica de aquellas escuelas públicas de 1900 se podría caracterizar, según Tiana Ferrer, como de apertura teórica a las nuevas corrientes, junto a una práctica por regla general trasnochada y poco renovadora ${ }^{18}$. La imagen que presentaban las escuelas privadas no resultaba muy distinta de la arriba descrita. Salvo en algunos centros, como la Institución Libre de Enseñanza, las Escuelas Pías y pocos más, los métodos de enseñanza eran anticuados y me- 
morísticos en exceso. Según la confesión religiosa, aquellas escuelas se clasificaron en 346 católicas, 18 de otras confesiones, y 4 laicas. Había, pues, una abrumadora mayoría de escuelas católicas, de las cuales únicamente 52 estaban regentadas por congregaciones religiosas (12 de varones y 40 de mujeres). El escaso número de centros laicos podría deberse a «la ausencia de organizaciones anarquistas, impulsoras de la escuela a- o antirreligiosa, y la acción limitada de grupos librepensadores o masones» ${ }^{19}$.

Las deficiencias escolares señaladas no impidieron que la población madrileña ofreciera unas elevadas tasas de alfabetización que contrastaban con las del conjunto nacional. En 1900 sólo el 44 por 100 de los censados mayores de diez años en España sabía leer y escribir (55 por 100 de los varones y 34 por 100 de las mujeres); en la capital madrileña, en cambio, ese porcentaje ascendía al 76 por 100 (88 por 100 de los varones y 67 por 100 de las mujeres). La presión social y las exigencias del mercado de trabajo fueron, sin duda, factores importantes para la extensión de la alfabetización, y en ese proceso la escolarización formal representó una de las vías, cada vez más consolidada, sin que ello supusiera merma alguna del predominio ejercido por la escuela privada ${ }^{20}$.

\section{Estudiantes y Profesores de Bachillerato}

Un simple vistazo a los edificios que albergaron los dos institutos que existían en Madrid en 1900 revelaba claramente que sus alumnos no pertenecían a las clases populares. La carrera escolar, aquélla que comprendía los estudios de Bachillerato y de Universidad, se había concebido en Europa y en España (aquí desde 1836) como algo destinado casi exclusivamente a las clases medias y altas de la sociedad. Ese carácter elitista, que seguía imperando a comienzos del siglo $\mathrm{XX}$, se manifestó en muchos aspectos, también en los locales destinados a la docencia. Si para establecer una escuela primaria sirvió en la España del siglo XIX cualquier local, los institutos, en cambio, se instalaron en edificios que, pese a no ser en la mayoría de los casos de nueva planta, daban prueba externa de solidez. En Madrid, el de San Isidro tuvo su origen en un Colegio fundado por los jesuitas en 1566, convertido luego en Colegio Imperial en recuerdo de la emperatriz doña María de Austria (hermana de Felipe II y bienhechora de la Compañía), y más tarde, tras la expulsión de los jesuitas en 1767, en Reales Estudios que se denominaron de San Isidro al ser trasladados a la iglesia del 
Colegio los restos del patrono de Madrid; y el Cardenal Cisneros se instaló en el antiguo Noviciado de la Compañía de Jesús (de ahí, el nombre que ostentó en el siglo XIX), un caserón de la calle Ancha de San Bernardo, donde también se ubicará la Universidad ${ }^{21}$. En el primitivo Colegio Imperial se situaron en el siglo XIX, además del instituto, la Escuela de Arquitectura, una de las secciones de la de Artes y Oficios, la clase de Química de varias Facultades (recordada por Pío Baroja en $E l$ árbol de la ciencia), y la biblioteca de Filosofía y Letras (cuyos 80.742 volúmenes de 1900 procedían, en parte, de la antigua biblioteca de los jesuitas) 22 . Todo aquel espacio formaba un complejo arquitectónico algo destartalado, pero monumental, en el que lucía sobre todo el magnífico patio del instituto, obra de Melchor de Bueras, «uno de los pocos barrocos que perduran en Madrid y que por sí solo dignifica todo el edificio» ${ }^{23}$.

La matrícula en el Bachillerato, supeditada a factores de índole económico y social, creció muy poco entre 1875 y 1900. En toda España se pasó de 28.551 estudiantes en 1876 (12.419 en la enseñanza oficial, 12.259 en la privada, y 3.873 en la libre) a 32.297 en 1900 (9.289 en la oficial, 17.000 en la privada y 6.008 en la libre) ${ }^{24}$. Si el número de matriculados aumentó sólo en la misma proporción que la población en su conjunto (en una y otra fecha se contaron 17 estudiantes por cada 10.000 habitantes), la distribución del alumnado, en cambio, varió sustancialmente, produciéndose un retroceso considerable de la enseñanza pública y el avance espectacular de la privada ${ }^{25}$. Ése era el estado numérico de la enseñanza media en España a comienzos del siglo XX, que provocó la reacción de García Alix y, en especial, de Romanones, artífice de una política reformista que tuvo como principal objetivo rescatar para la enseñanza pública el alumnado que había perdido ${ }^{26}$. La situación en Madrid era algo dịstinta a la del Estado. La matrícula había crecido también muy poco (4.050 alumnos en 1877, 4.665 en 1900), pero relativamente mucho menos de lo que lo hizo la población madrileña en las mismas fechas, de manera que si en 1877 (población: 397.816) había en la capital 102 estudiantes de Bachillerato por cada 10.000 habitantes, la proporción había caído a 87 en 1900 (población: 539.835). Desde esa fecha, el crecimiento fue más acusado, y ya en 1915, con 8.358 estudiantes y una población de 656.197, la relación era de 128 alumnos por cada 10.000 habitantes ${ }^{27}$. En la distribución de la matrícula, las diferencias de Madrid con respecto al promedio nacional eran de orden cuantitativo, con la salvedad cualitativa de que la enseñanza privada en la capital fue siempre superior numéricamente a la pública durante la Restauración. 
Madrid contaba en 1900, aparte de los dos institutos, con 98 colegios incorporados (92 dirigidos por seglares y 6 por religiosos) donde poder cursar el Bachillerato. De las tres modalidades de matrícula existentes (oficial, privada y libre), los padres de familia optaron mayoritariamente por la enseñanza privada, que llegó a representar en ese año casi el 66 por 100 de la matrícula total (43,8 por 100 los seglares y 22 por 100 los religiosos, de jesuitas y escolapios, principalmente). Razones de diversa naturaleza, entre las cuales las sociológicas no fueron pequeñas, justificaron aquella elección. Llevar a los hijos a un determinado centro (por ejemplo, el de Nuestra Señora del Recuerdo de Chamartín, regentado por los jesuitas) constituía un signo de identidad y un elemento más de cohesión de las clases acomodadas de la sociedad madrileña. Cierto era que en aquellos colegios de élite se atendía con más solicitud que en la enseñanza oficial a la educación artística, la música, el dibujo, los deportes, los viajes culturales, en algunos centros también a la formación religiosa, en todos a la disciplina. En los institutos, por lo general, los profesores cumplían su misión con sólo explicar en las horas asignadas las materias en las que eran especialistas, sin que se llegara a establecer «la verdadera fraternidad que debe haber entre el alumno y el profesor» ${ }^{28}$. En los colegios privados, esa «fraternidad» tampoco era que se alcanzara de manera general, pero sí había una vigilancia mucho más enérgica que en los institutos sobre el alumnado y su proceso de aprendizaje. Así, aquellos profesores de la enseñanza privada (de los que sólo tenían título académico algo menos de la mitad, y ninguno de los religiosos ${ }^{29}$ ), preparaban a sus alumnos fundamentalmente para los exámenes oficiales, en los que solían conseguir buenos resultados. Un centro privado excepcional fue la I.L.E., que ya en el curso 1880-1881 apostó por la fusión definitiva de la primera y la segunda enseñanza (algo que ha recuperado la L.O.G.S.E de 1990), una propuesta renovadora que fue aplicada por un profesorado de notable calidad. Los principios que orientaron la obra educativa de Giner de los Ríos, absolutamente válidos igualmente para nuestro tiempo, podrían reducirse, siguiendo a Carlos Paris, a los cuatro siguientes: 1) el ideal de libertad; 2) la comprensión vital del acto educativo; 3) la unidad metodológica de todo el proceso de enseñanza; y 4) el carácter integral, profundamente humanista, de la educación ${ }^{30}$. (Con aquellos principios comulgaron también bastantes profesores de la enseñanza pública de comienzos del siglo).

Los dos institutos de Madrid acogieron en 1900 a 911 alumnos oficiales, todos varones, (449 en San Isidro y 462 en Cardenal Cisneros), esto es, el 19,5 por 100 de la matrícula total. Sin embargo, todos los 
Madrid 1900. La capital del sistema educativo

alumnos del Bachillerato, lo mismo de colegios incorporados que libres, debían examinarse en los centros públicos para validar sus cursos. (En el curso 1901-1902 fueron expedidos 261 títulos de Bachiller en el Cardenal Cisneros y 144 en San Isidro). Esa exigencia académica, y el nivel intelectual que tenía el profesorado oficial, conferían a los institutos de entonces un prestigio grande, y a sus catedráticos una alta consideración social. En San Isidro ejercían en el curso 1899-1900, entre otros, Elías Alfaro Navarro (Latín y secretario del instituto), Ricardo Becerro de Bengoa (Química), Manuel Burillo de Santiago (Matemáticas), José Ceruelo Obispo (Matemáticas y director del centro), Urbano González Serrano (Psicología, Lógica y Filosofía moral), Eugenio Méndez Caballero (Latín), Francisco Navarro Ledesma (Retórica y Poética), Federico Requejo Avedillo (Agricultura; pasó en noviembre de 1899 al Cardenal Cisneros), Demetrio Fidel Rubio Alberto (Historia Natural), Justo Sales Esteban (Francés), y Mariano Tortosa Picón (Agricultura), (Manuel Zabala se incorporó en 1900-1901 para ocupar la vacante de Geografía e Historia); y en el Cardenal Cisneros, Fernando Araujo Gómez (Francés), Narciso Campillo Correa (Retórica y Poética), Serafín Casas Abad (Historia Natural), Francisco A. Commelerán Gómez (Latín y director del Instituto), Antonio López Muñoz (Psicología, Lógica y Filosofía moral), Mario Méndez Bejarano (Francés), Manuel Merelo Calvo (Geografía e Historia de España), José Muro López-Salgado (Geografía e Historia de España), Rodrigo Sanjurjo Izquierdo (Física y Química y secretario del centro), Enrique Serrano Fatigati (Física y Química), Emeterio Suaña Castellet (Latín), e Ignacio Suárez Somontes (Matemáticas) ${ }^{31}$.

Aquellos catedráticos de 1900 respondían a las señas que siguen: habían nacido entre 1827 (Merelo) y 1869 (Navarro Ledesma), la mayoría en una capital de provincias ( 15 incluidos 4 de Madrid), eran mayoría relativa los de la región castellano-leonesa (7), predominaban los de edades comprendidas entre 41 y 50 años de edad, casi la mitad había realizado otra carrera y alcanzado el título de doctor, se habían hecho catedráticos por oposición antes de los 35 años (y la mitad antes de los 30), estaban cargados de años de servicio (14 con más de 25 años de servicio), habían llegado a los institutos de Madrid mayoritariamente por concurso y después de 1886 (pero dos ocupaban ya la cátedra desde los años 1850-1860 y tres más desde el Sexenio). Como catedráticos, cobraban sueldos comprendidos entre 4.500 y 7.500 pesetas anuales, vivían en pisos por los que pagaban alquileres mensuales de 75 a 150 pesetas, tenían 1 ó 2 sirvientas, y lógicamente (dado el sueldo oficial) desarrollaban otras actividades, además de la docente ${ }^{32}$. Casi todos habían escrito 
al menos una obra de texto, algunos además eran autores de monografías (científicas/divulgación) referidas a su especialidad, a la educación o a la cuestión social (González Serrano, Becerro, Ceruelo, Casas, Serrano Fatigati, Navarro Ledesma, Rubio, Araujo, Méndez Bejarano). Algunos habían ejercido cargos en la Administración (Merelo y Muro, por ejemplo, eran ex ministros del Sexenio, y el primero además jubilado del Consejo de Estado), y la mayoría había formado parte de comisiones diversas. En aquella plantilla había en 1900 parlamentarios (Muro y Requejo en el Congreso, y Merelo — vitalicio- y Commelerán - por Segoviaen el Senado), consejeros de instrucción pública (Becerro, López Muñoz, Araujo), académicos (Commelerán, de la Española; Becerro, de Ciencias y correspondiente de la de Historia junto a Muro y Araujo), y en 1902 Requejo llegará a subsecretario de Instrucción Pública (a gobernador civil de Madrid más tarde), y Antonio López Muñoz ejercerá de ministro a partir de diciembre de 1912; en la prensa escribieron muchos, pero quien destacó realmente fue Navarro Ledesma (18691905), que a su faceta de catedrático unió la de archivero (ayudante de segundo grado con licencia reglamentaria en 1900), divulgador cervantista de éxito, y periodista de diversas publicaciones, la más importante $E l G l o b o$, de la que fue redactor clave tras la compra del periódico por Romanones ${ }^{33}$.

\section{La Universidad Central, término de la carrera escolar y docente}

En el curso 1900-1901 se matricularon en la Universidad española 17.230 estudiantes (16.874 en 1878-1879), de los cuales 4.797 ( 27,8 por 100) lo hicieron en la Universidad de Madrid, lo que daba, en el caso de España, una proporción de 9 estudiantes universitarios por cada 10.000 habitantes, y 23 en el distrito de Madrid (que comprendía las provincias de Madrid, Ciudad Real, Cuenca, Guadalajara, Segovia y Toledo). La Universidad de entonces seguía respondiendo al modelo burocrático-administrativo, centralista y uniforme, impuesto por los liberales en el siglo XIX, un modelo (mala copia del francés) que acabó con la autonomía de la Universidad y limitó su función «a una preparación para los diplomas, cerrándose a toda investigación desinteresada o desentendida de dicho objeto» ${ }^{34}$. En ese modelo, la Central ocupaba, como se dijo, la cúspide del sistema, la que monopolizó la enseñanza del doctorado y la única que dispuso de todas las secciones de licenciatura, que se implantaron en España tras la reforma de 
García Alix en 1900. De ahí, aunque no sólo por eso, la mayor concentración de estudiantes en la capital del Estado. En la Central, en efecto, estaba matriculado el 40,1 por 100 de todos los alumnos de Farmacia, el 31,3 por 100 de los de Derecho, el 26,8 por 100 . de los de Filosofía y Letras, el 24,2 por 100 de los de Medicina, y el 21,5 por 100 de los de Ciencias (sólo aquí era superada por la Universidad de Barcelona, que agrupó el 31 por 100) ${ }^{35}$.

En España, y también en Madrid, los estudiantes universitarios se matricularon mayoritariamente en la enseñanza no oficial (8.262 oficiales y 8.968 libres en España; 2.130 oficiales y 2.667 libres en Madrid); sólo en aquellas Facultades en las que se suponía teóricamente el carácter práctico de sus estudios, como Medicina, Farmacia y Ciencias, fue superior la matrícula oficial a la libre. La distribución de aquel alumnado presentaba en la capital, lo mismo que en el conjunto nacional, unas características que ya venían de atrás: predominio de los estudiantes de Derecho (relativamente más en la capital) y de Medicina (en Madrid algo menos que en el resto, no obstante lo cual significaron en el curso de referencia la cuarta parte del total), y alza creciente de la matrícula en Ciencias y, en menor medida, en Filosofía y Letras, mientras que la de Farmacia permaneció prácticamente estancada.

Las Facultades madrileñas estaban situadas en medio de la ciudad. Medicina se hallaba en la calle Atocha, en el antiguo Colegio de Cirugía de San Carlos y junto al Hospital General, Farmacia en la calle de su nombre, y las tres restantes, Derecho, Ciencias y Filosofía y Letras, en la calle de San Bernardo, que era la sede central de la Universidad. La escasez de locales y laboratorios dificultaba seriamente la actividad docente de aquella Universidad. De todas las Facultades, la de Ciencias resultaba probablemente la más afectada por esa carencia, sus clases se impartían en San Bernardo, otras en el instituto de San Isidro, otras en el Museo de Ciencias naturales (radicado desde 1895 en el edificio de la Biblioteca Nacional) o en el Jardín Botánico. Un informe firmado por el claustro de esa Facultad en febrero de 1898 afirmaba que «las circunstancias y condiciones relativas a los locales destinados a cátedras y laboratorios son extremadamente deplorables» ${ }^{36}$, y el estudio de Fernando Araujo publicado cinco años más tarde hacía hincapié en que lo que le faltaba a la Universidad en España (también a la Central), y ahí radicaba «la verdadera causa de la frecuente esterilidad de la labor docente», era "material de enseñanza (locales y material fijo y móvil) y organización adecuada de las Prácticas en las clases experimentales» ${ }^{37}$. La localización de la Universidad en lugares céntricos de la capital contribuyó en alto grado a alterar la morfologíá 
de aquellas calles y la vida de sus residentes. Se fueron instalando casas de huéspedes, tiendas de libros, academias preparatorias, cafés y billares, y los alrededores de la Universidad se convirtieron prácticamente en un espacio dominado por los estudiantes, escenario de múltiples trifulcas por los motivos más dispares (en 1900, contra la boda proyectada de la princesa de Asturias con el segundogénito del general carlista y pretendiente a la corona de Nápoles, conde de Caserta), que cada vez estorbaban más la vida pacífica del vecindario ${ }^{38}$. Por esa razón, y también porque era necesario ampliar los edificios destinados a Facultades, se empezó a pensar por esos años en construir un campus universitario alejado de la ciudad; el proyecto, sin embargo, no prosperó hasta 1927, comenzándose al año siguiente las obras (bajo la dirección del arquitecto López Otero) de lo que pasados unos años será la Ciudad Universitaria, sede de varias Facultades de la actual Universidad Complutense ${ }^{39}$.

La Central venía a ser por esos años, como ya se indicó, la Universidad que mejor representaba, por el número y la procedencia de sus estudiantes y profesores, al conjunto de España. Unos y otros llegaron a la capital no sólo porque en ella se impartían todas las licenciaturas y el doctorado, sino también porque Madrid, capital del Estado, ofrecía mayores oportunidades vitales a los recién graduados, y posibilidades infinitas a los profesores para poder desarrollar otras facetas de su personalidad, además de la docente. De los 379 alumnos que recibieron el grado de licenciado en el curso 1901-1902 habían nacido en Madrid 97 (25,6 por 100), y 50 más (13,2 por 100) en las provincias del distrito universitario; eran, por consiguiente, mayoría los 232 (61,2 por 100) que procedieron del resto de España, entre los que abundaron los de Castilla-León (sin contar Segovia, incluida en el distrito universitario de Madrid, sumaron 56), Andalucía (34), y Extremadura (27), pero los hubo también de la región valenciana, del País Vasco, Aragón, Murcia, Asturias, Navarra, Baleares y Canarias, Galicia, Logroño, Cataluña, y el extranjero (2 de Francia, y 6 de Hispanoamérica y Filipinas). (En conjunto, 170 venían de las capitales y 209 de sus respectivas provincias). Madrid fue lógicamente la Universidad que más licenciados aportó (42 alumnos) a la graduación de doctor que en 1902 alcanzaron 159 estudiantes; le seguían los licenciados por Barcelona (29 alumnos), Valencia (18), Valladolid (16), Zaragoza (16), Salamanca (11), Santiago (8), Sevilla (8), Granada (6), Oviedo (4), y la privada de Sacro Monte (1) ${ }^{40}$. La coincidencia en la Universidad de jóvenes de distintas clases y procedencias constituía una vía inmejorable para conocer otras culturas, y para formarse una idea de 
lo que era la vida provinciana. En las aulas universitarias se podía aprender lo fundamental de cada disciplina, pero el frecuentarlas, como recordará Romanones, servía además, y en no poca medida, "para comenzar a conocer la vida y los hombres; pues no hay nada más provechoso para esto que el trato y la amistad entre estudiantes» ${ }^{41}$.

El personal docente de la Universidad de Madrid en 1900 estaba formado, según la Guía oficial de España, por 90 catedráticos (15 en Filosofía y Letras, 19 en Medicina, 26 en Ciencias, 9 en Farmacia, y 21 en Derecho), y un número de auxiliares y ayudantes (no aparecían en la Guía) que no sería superior a $40^{42}$. Era entonces Rector de la Universidad (el mandato duró de 1895, en que sucedió a Pisa Pajares, hasta 1903) Francisco Fernández González (1833-1917), catedrático de Estética en la Facultad de Filosofía y Letras desde 1864; y enseñaban en ella, entre otros, Menéndez Pelayo, Morayta Sagrario, Nicolás Salmerón, Antonio Sánchez Moguel, Manuel Ma del Valle (Filosofía y Letras), Ramón y Cajal, Calleja, Jiménez García, Alejandro San Martín, Federico Olóriz (Medicina), Gumersindo Azcárate, Giner de los Ríos, Montejo Rica, Piernas Hurtado, Santamaría de Paredes (Derecho), Eduardo Torroja, Ignacio Bolívar, Muñoz del Castillo, Octavio de Toledo, Miguel Vegas (Ciencias), Lázaro e Ibiza, Rodríguez Carracido (Farmacia). La aplicación de las reformas de García Alix en las Facultades de Filosofía y Letras y Ciencias, con el aumento de secciones y de asignaturas, se tradujo en un incremento de la plantilla de Madrid, que en el curso 1901-1902 ya era de 105 catedráticos (23 en Filosofía y Letras, 34 en Ciencias, 20 en Derecho, 19 en Medicina, y 9 en Farmacia) y 50 auxiliares y ayudantes. Entre los recién incorporados figuraban, por ejemplo, Manuel Sales y Ferré (el primer titular de la nueva cátedra de Sociología), Juan Catalina García, Antonio Hernández Fajarnés, Ramón Menéndez Pidal (Filosofía y Letras), Cecilio Jiménez Rueda, Eduardo Lozano Ponce de León (Ciencias) ${ }^{43}$. Madrid reunió, pues, en torno a la cuarta parte de los catedráticos de la Universidad española; Barcelona, la segunda Universidad en España por el número de sus alumnos, resultaba proporcionalmente menos dotada (55 catedráticos en 1900), hasta el extremo de que su Facultad de Ciencias, con una matrícula 44 por 100 más elevada que la madrileña, contaba con menos de la mitad de los catedráticos de la Central. La superabundancia de catedráticos en Madrid tenía una razón académica (la exclusiva del doctorado), pero se debió en mayor medida al desdoblamiento de determinadas asignaturas de la licenciatura, que se practicó, en ocasiones infundadamente, con el argumento de una matrícula excesiva. Así, reconocerá Santiago Alba en 1918, cuando defendía en el 
Congreso su decreto sobre jubilaciones y amortizaciones, «mediante la división, sin sumisión al régimen general de cátedras, se traía a quien el Ministro quería traer a Madrid», llegando a afirmar (y entonces era Alba el ministro de Instrucción) que «en la mayor parte de los Centros de enseñanza de Madrid, muchas cátedras no se han creado en los últimos años mirando a los intereses pedagógicos del país, sino mirando a las conveniencias de unos cuantos señores a quienes convenía ser catedráticos en la Corte» ${ }^{44}$.

Los catedráticos de Madrid en 1900 presentaban las señas que siguen ${ }^{45}$ : habían nacido entre 1826 (fecha de nacimiento de Juan Manuel Ortí y Lara -dejará la docencia al terminar el curso 1899-1900) y 1874 (Faustino Archilla Salido, llegado a Madrid en el curso 1900-1901), predominando los nacidos entre 1841 y 1860, por tanto, los que contaban en 1900 entre 40 y 59 años de edad; el lugar de nacimiento, por orden de importancia numérica, era Madrid (16 de 68 casos), Castilla-León, y Andalucía, pero los había de todas las regiones españolas (más de las capitales que de las provincias); la mayoría había obtenido la cátedra de Madrid a partir de 1886, y después de una estancia más o menos larga en las Universidades de provincias; sus sueldos como catedráticos estaban comprendidos, según dejaron constancia en el padrón municipal, entre 4.500 pesetas al año (Lázaro e Ibiza, por ejemplo) y 11.000 (Rojas Caballero-Infante), siendo los más frecuentes los de 6.000 (Salvador Calderón Arana), 7.000 (Matías Barrio Mier), 7.500 (Amalio Gimeno), y 8.500 (Gumersindo Azcárate, Francisco Giner de los Ríos). (A los sueldos de catedráticos, habría que añadir, en su caso, otros ingresos como los procedentes del ejercicio social de la profesión, y/o las rentas derivadas de la propiedad urbana/rústica -que algunos profesores indicaron indirectamente en el padrón, incluyendo la cuota abonada por contribución industrial/territorial - y/o del capital mobiliario, además de los derechos de examen y los de autoría de libros) ${ }^{46}$.

La forma en que aquellos catedráticos estaban instalados en Madrid también presentaba diferencias, en algunos casos muy notables. Una minoría vivía como decía Ramón y Cajal que lo hacían algunos de los catedráticos recién llegados a la Corte, «a lo dentista americano», esto es, "gastando sus modestos ahorros en costearse coche, habitación y mueblaje, en espera de una clientela opulenta que no se digna comparecer»; el padrón dió razón de semejante conducta mediante unos alquileres de pisos principales que superaban las 225 pesetas mensuales y un servicio doméstico que estaba compuesto por tres o cuatro personas cualificadas (criados, doncellas, cocineras, nodrizas). Otra minoría, por 
el contrario, se instaló en viviendas que costaban menos de 70 pesetas de alquiler, y sin servicio doméstico, en unas condiciones excesivamente modestas que alguna gente "hinchada" calificaba de impropia de un príncipe de la toga académica» ${ }^{47}$. Pero la mayoría de aquellos catedráticos residía en los distritos de Congreso, Buenavista, Centro, y Hospicio, pagaba entre 90 y 150 pesetas de alquiler y contaba con una o dos sirvientas. Pertenecían a la nobleza Andrés del Busto y López (marqués del Busto), catedrático de Obstetricia, Francisco J. González de Castejón y Elío (marqués de Vadillo), catedrático de Derecho natural y ministro en varias ocasiones a partir de mayo de 1900 , y Francisco de P. Jiménez y Pérez de Vargas (marqués de la Merced), llegado a la Central el curso 1901-1902 para ocupar la cátedra de Economía política en la Facultad de Derecho (al desdoblarse la que regentaba José $\mathrm{M}^{\mathrm{a}}$ Olózaga); y serán más tarde ennoblecidos Calleja (1912), Gimeno (1920), Santamaría de Paredes (1920), el catedrático de instituto López Muñoz (1920), y Ramón y Cajal (1952). Muchos más serán concesionarios por «los relevantes servicios prestados a la cultura nacional» de premios, como la Gran Cruz de la Orden Civil de Alfonso XII, pero de los profesores de aquel claustro quizá ninguno como Santiago Ramón y Cajal había sido capaz de desarrollar para 1900 una carrera científica de relieve internacional. En ese año (después de haber sido ya objeto de varias dintinciones en Europa) recibió Cajal el premio Moscú otorgado por el Congreso Internacional de Medicina, reunido en París; la concesión de ese importante premio sirvió no sólo para consagrar oficialmente a Cajal en España (Gran Cruz de Isabel la Católica, Gran Cruz de Alfonso XII, prensa), sino también para que el Gobierno aprobara la creación de un Laboratorio de Investigaciones Biológicas, que se inauguró en 1901, instalándose provisionalmente en la calle Ventura de la Vega, y definitivamente desde 1902 en un edificio contiguo al Museo Antropológico (fundación del doctor Pedro González de Velasco), en la calle Atocha. (En la carrera creciente de éxitos científicos y de reconocimientos de Cajal, otra fecha clave fue 1906, año en el que compartió el Premio Nobel con Camillo Golgi).

La multiplicidad de facetas fue característica bastante común de los catedráticos de 1900. Limitándonos a la información contenida en la Guía oficial de España, en 1900 figuraban catedráticos en el Parlamento, en el Gobierno civil, en el Cuerpo facultativo de Archiveros, Bibliotecarios y Anticuarios, en las Academias y en el Consejo de Instrucción pública. En el Senado: eran vitalicios Eugenio Montero Ríos y Augusto Comas; por las Universidades: Alejandro San Martín (Madrid), Felipe Sánchez Román (Granada), Eduardo Hinojosa (Santiago), 
Amalio Gimeno (Valencia) y Julián Calleja (Zaragoza); por provincias: marqués de la Merced (Jaén) y Francisco Fernández González (Pontevedra); en el Congreso: Gumersindo Azcárate (por León), Matías Barrio (Palencia), Francisco J. González de Castejón (Pamplona) y Miguel Morayta (Valencia). En el Gobierno civil de Madrid estaba de secretario Miguel García Romero (catedrático de Geografía política y descriptiva a partir de 1900-1901). El escalafón del Cuerpo de Archiveros... comprendía a Marcelino Menéndez Pelayo como Jefe superior (dejará la docencia universitaria en septiembre de 1900), Vicente Vignau (inspector tercero y catedrático de Latín vulgar en 1900-1901), Eduardo Hinojosa Naveros, Juan Catalina García, Mariano Muñoz Rivero y Cayo Ortega Mayor (Jefes de primer grado y catedráticos a partir de 1900-1901 en la Facultad de Filosofía y Letras). Eran académicos en 1900: en la Real Academia Española, Menéndez Pelayo, Miguel Colmeiro, y Fernández González; en la de la Historia, Fernández González, Codera Zaidín, Menéndez Pelayo (bibliotecario), Sánchez Moguel, Hinojosa Naveros, Catalina García, Vignau Ballester, electos Manuel $\mathrm{M}^{\mathrm{a}}$ del Valle y Gumersindo Azcárate, y correspondientes en Madrid Salvador de Torres Aguilar, Juan Ortega Rubio (y lo fue hasta su fallecimiento Francisco de la Pisa Pajares); en la de Bellas Artes, Fernánidez González y Menéndez Pelayo (electo); en la de Ciencias Exactas, Físicas y $\mathrm{Na}$ turales, Eduardo Torroja, Gabriel de la Puerta, José Rodríguez Carracido, Francisco P. Rojas, Miguel Colmeiro, Joaquín González Hidalgo (contador de la Academia), Julián Calleja, Santiago Ramón y Cajal, e Ignacio Bolívar (electo); en la de Ciencias Morales y Políticas, Eugenio Montero Ríos, Gumersindo Azcárate, Menéndez Pelayo, Santamaría de Paredes, Ortí y Lara, Segismundo Moret, y electos Hinojosa y Comas; en la de Medicina, Miguel Colmeiro (vocal), Julián Calleja, Federico Olóriz, Alejandro San Martín, José Ribera Sans, Gabriel de la Puerta (vocal), Julián Casaña Leonardo, Juan Ramón Gómez Pamo, Benito Hernando Espinosa, y electos Teodoro Yáñez, Ramón y Cajal, Amalio Gimeno, Fausto Garagarza y Manuel Alonso Sañudo, (había sido académico de número Andrés del Busto). Finalmente, eran consejeros de Instrucción pública: Calleja, Gabriel de la Puerta, Menéndez Pelayo, Ignacio Bolívar, Alejandro San Martín, Mariano Viscasillas, Gonzalo Quintero, Matías Barrio, Rafael Conde Luque, Faustino Álvarez del Manzano, José de Castro Pulido, José Rodríguez Carracido, Santiago Ramón y Cajal, Gumersindo Azcárate, y Antonio Sánchez Moguel.

Las actividades arriba indicadas constituían una muestra (parcial) de los intereses que pudieron ser satisfechos en la capital del Estado. Aquellos catedráticos universitarios se dedicaron a muchas cosas, ade- 
más de atender a sus clases. De ahí, que la crítica suscitada a raíz de 1898 hiciera también hincapié en la figura del profesor: entre otras cosas, se les recordará a los catedráticos que ejercían la abogacía o la medicina, y a los que se dedicaban a la política o a cualquier otro asunto «que ante todo y sobre todo» eran catedráticos, «y si alguna vez lo olvidan, la Administración debe recordárselo empleando severos correctivos, sea quien quiera el culpable» ${ }^{48}$.

\section{Notas}

1 Santiago Ramón y Cajal: Recuerdos de mi vida: Historia de mi labor científica, Madrid, Alianza Editorial, 1981, pp. 128-131; sobre la consideración social de los catedráticos de la Central, Marcelo Rivas Mateos, catedrático de Farmacia y discípulo de Lázaro e Ibiza, Discurso leido en la solemne inauguración del curso académico de 1912 a 1913: El Profesorado Universitario, Madrid, Imp. Colonial, 1912, p. 25.

2 Mariano Hormigón: "Las Matemáticas en España en el primer tercio del s. XX", en José Manuel Sánchez Ron (ed.): Ciencia y sociedad en España: de la Ilustración a la Guerra Civil, Madrid, El Arquero, CSIC, 1988, p. 273.

3 R.D. de 18 de mayo 1900; Antonio García Alix: Disposiciones dictadas para la reorganización de la enseñanza, Madrid, Imprenta del Colegio Nacional de Sordomudos y de Ciegos, 1900, p. X.

4 En las redes caciquiles estuvieron integrados también algunos de los profesores de Madrid, distinguiéndose en esa actuación por encima de todos Federico Requejo y Avedillo, ingeniero agrónomo, catedrático del Instituto de San Isidro, y heredero liberal del distrito de Bermillo de Sayago (Zamora); y en el ámbito universitario, Julián Calleja y Sánchez, decano y catedrático de la Facultad de Medicina, que ejercía una influencia al parecer "omnímoda e irresistible» en la provisión de cátedras de Medicina.

5 Francisco Villacorta Baños: «Instituciones culturales, sociedad civil e intelectuales en el Madrid de la Restauración», y Paul Aubert: "Madrid, polo de atracción de la intelectualidad a principios de siglo", ambos publicados en Ángel Bahamonde Magro y Luis Enrique Otero Carvajal (eds.), La sociedad madrileña durante la Restauración, 1876-1931, vol. II, Madrid, 1989, pp. 79-99 y 101-137, respectivamente.

6 A. García Alix, op. cit., p. VII; el subrayado es mío.

7 Llegaron a ser ministros los profesores del Cardenal Cisneros Manuel Merelo (1872), José Muro (1873), y Antonio López Muñoz (1912, 1913, 1923), y los de la Central Nicolás Salmerón (1873), Francisco J. González de Castejón, marqués de Vadillo (1900, 1900-1901, 1902-1903, 1904-1905), Felipe Sánchez Román (1905), Vicente Santamaría de Paredes (1905-1906), Alejandro San Martín (1906), Amalio Gimeno (entre 1906 y 1920, en ocho ocasiones), Joaquín Fernández Prida (1917-1918, 1919-1920, 1921, 1922), y Tomás Montejo (1921, 1922); a los senadores, se les cita en el texto principal más adelante.

${ }_{8} \mathrm{M}^{\mathrm{a}}$ Dolores Gómez Molleda: Los Reformadores de la España contemporánea, Madrid, CSIC, 1966, cap. XIII. 
9 En el padrón municipal de 1900 he podido encontrar las hojas correspondientes a más de la mitad del profesorado (de Instituto y de Universidad) que figura en la Guía oficial de España. 1900, Madrid, Viuda de M. Minuesa de los Ríos, 1900, pp. 617 ss.

10 Los datos sobre escolarización proceden de Alejandro Tiana Ferrer: «Alfabetización y escolarización en la sociedad madrileña de comienzos del siglo XX, 1900-1920", en Á. Bahamonde y L. E. Otero, op. cit., p. 215; del mismo autor: Maestros, misioneros y militantes. La educación de la clase obrera madrileña, 1898-1917, Madrid, MEC, 1992.

11 Los comentarios se han hecho sobre los datos de Alejandro Tiana («Alfabetización..., op. cit., p. 215; y Maestros..., op. cit., p. 153). El autor señala con razón dos advertencias a la hora de tratar el problema en sus términos cuantitativos: la precaria exactitud de las fuentes estadísticas de aquel tiempo, y la imprecisión en la que se puede incurrir al fijar las cifras de escolarización al existir un número de alumnos de 10-12 años cursando estudios de Bachillerato.

12 Tiana, Maestros..., op. cit., p. 138; en adelante, las referencias se remiten siempre a esta obra. Para el conjunto nacional, Estíbaliz Ruiz de Azúa: "La escuela pública liberal», en Antonio Fernández García (coord.): Los fundamentos de la España liberal (1834-1900). La sociedad, la economía y las formas de vida, Madrid, Espasa Calpe, 1997, tomo XXXIII de la Historia de España. Menéndez Pidal-Jover Zamora, p. 793.

13 Ministerio de Instrucción Pública y Bellas Artes: Censo escolar de España, Madrid, Imp. del Instituto Geográfico y Estadístico, 1904.

14 Jimeno Agius, La Instrucción primaria en España. Estudio estadístico, Madrid, 1885.

15 Estíbaliz Ruiz de Azúa: «El gasto municipal en educación (1886-1892). Un análisis comparado de los presupuestos en Vitoria y en Madrid", en Luis Miguel Villar (ed.): 25 años. Facultad de Filosofía y Letras. II. Estudios de Geografía e Historia, Bilbao, Universidad de Deusto, 1988, pp. 627-645.

16 Estíbaliz Ruíz de Azúa: «La Instrucción Pública y las clases trabajadoras en Madrid, 1883-1903", en El Reformismo social en España: la Comisión de Reformas Sociales, Córdoba, Cajasur, 1987, pp. 240-241; y, sobre todo, Tiana, op. cit., pp. 155 ss.

17 En Tiana, op. cit., p. 171; en la misma página se indica que el presupuesto trimestral para material ascendía a 101 pesetas por clase en 1903, y en él se incluían el pago de la limpieza y la calefacción, y la compra de libros, papel, plumas, tinta, y otros enseres escolares.

18 Tiana, op. cit., pp. 172 ss.

19 Tiana, op. cit., p. 164. Como dice el autor, el estudio de la enseñanza privada en Madrid en aquellos años está prácticamente todavía a medio investigar.

20 Datos de la situación en los años 1980, Francisco Bosch y Javier Díaz: La educación en España. Una perspectiva económica, Barcelona, Ariel, 1988, p. 89.

21 Ramón Ezquerra Abadia: Recuerdos del Instituto de San Isidro, (Aula de Cultura del Ayuntamiento de Madrid), Madrid, Artes Gráficas Municipales, 1984; Ramón de Mesonero Romanos: El antiguo Madrid. Paseos histórico-anecdóticos por las calles y casas de esta Villa, Madrid, ed. facsímil, 1981, pp. 296-297; el calificativo de Ancha aplicado a la calle de San Bernardo se suprimió en 1865 (Hilario Peñasco de la Puente y Carlos Cambronero: Las calles de Madrid. Noticias, tradiciones y curiosidades, Madrid, ed. facsímil de la editada por vez primera en 1889 , p. 452). 


\section{Madrid 1900. La capital del sistema educativo}

22 Los orígenes de la Biblioteca, en Anuario del Estudiante, Madrid, 1877, p. 50; el número de volúmenes de 1900, en Universidad Central de España: Memoria del curso de 1901 a 1902 y Anuario del de 1902 a 1903 de su distrito universitario, Madrid, Imp. colonial, 1903, p. 70.

23 Ramón Ezquerra, op. cit., p. 8; Virginia Tovar: Arquitectos madrileños de la segunda mitad del siglo XVII, Madrid, Instituto de Estudios Madrileños, 1975, pp. 365-373.

24 Ministerio de Instrucción Pública y Bellas Artes: Anuario Estadístico de Instrucción Pública correspondiente al curso de 1900-1901, con avances de 1902 y 1903, Madrid, 1904, pp. 246-247.

25 Ib., pp. 226-227.

26 Algo se consiguió de manera inmediata: en 1915 la matrícula de Bachillerato en España ascendió a 43.471 alumnos (13.707 en la enseñanza oficial, 10.337 en la privada, y 19.427 en la libre).

27 Los datos de la población madrileña de 1877 y 1900, en Antonio Fernández y Ángel Bahamonde: "La sociedad madrileña en el siglo XIX», en Antonio Fernández García (dir.): Historia de Madrid, Madrid, Ed. Complutense, 1993, p. 481; el de 1915, en Tiana, op. cit., p. 23.

28 Diario de Sesiones del Congreso de los Diputados, 11 de mayo de 1895, p. 3584, intervención de Vincenti (ex alumno de colegio y de instituto en Madrid); para la actuación de los jesuitas en la enseñanza media, Manuel Revuelta González, Los colegios de jesuitas y su tradición educativa (1868-1906), Madrid, UPCo, 1998.

29 Anuario (1904), op. cit., pp. 226-227.

30 Carlos Paris: "Las ideas pedagógicas de don Francisco Giner», en AA.VV.: En el centenario de la Institución Libre de Enseñanza, Madrid, Tecnos, 1977, p. 59; para los orígenes de la Institución, Vicente Cacho Viu: La Institución Libre de Enseñanza. I. Orígenes y etapa universitaria (1860-1881), Madrid, Rialp, 1962; para su valoración educativa, $\mathrm{M}^{\mathrm{a}}$ Dolores Gómez Molleda, op. cit.; e Yvonne Turin: La educación y la escuela en España de 1874 a 1902. Liberalismo y tradición, Madrid, Aguilar, 1967, pp. 175 ss.

31 La nómina está sacada de la Guía..., op. cit., pp. 644-645; completaban la lista Bernardo Rodríguez (Física y Química), Julián Pereda (Religión), y Francisco de la Macorra (Gimnástica), en San Isidro, y en el Cardenal Cisneros, Miguel Martínez (Matemáticas), Laureano Rodríguez (Religión) y Eduardo Serrano Fatigati (Gimnástica). Trece de esos profesores causaron baja en los años siguientes: por jubilación, Casas, Merelo y Suaña (1900); y por defunción, Campillo (1900), Becerro (1902), Ceruelo (1903), Méndez Caballero, Fraile, y Navarro Ledesma (1905), Sales, Muro, y Sanjurjo (1907), y Rubio (1908). Las asignaturas que se mencionan correspondían al Plan de Estudios vigente en 1899-1900 del ministro Luis Pidal; en 1900-1901 entró en vigor el nuevo Plan de García Alix, que fue a su vez reformado por Romanones en el curso 1901-1902; de ahí, las distintas denominaciones de asignaturas adjudicadas al Profesorado en los dos cursos siguientes a 1899-1900.

32 Las señas proceden de los expedientes personales de los profesores mencionados en el texto principal que se han consultado en el Archivo General de la Administración (Alcalá de Henares), y del Padrón municipal de 1900, en Archivo de Villa, Estadística.

33 Javier Moreno Luzón: Romanones. Caciquismo y política liberal, Madrid, Alianza Editorial, 1998, p. 109; mucho más espacio obviamente se dedica a las actividades de Federico Requejo. 
34 Francisco Giner de los Ríos: Ensayos (selección, ed. y prólogo de Juan LópezMorillas), Madrid, Alianza Editorial, 1969, p. 130; José Luis Peset y otros: Historia y actualidad de la Universidad Española, Madrid, Fundación March, 6 vols., 1984; Elena Hernández Sandoica: «Cambios y resistencias al cambio en la Universidad española (1875-1931)", en José Luis García Delgado (ed.): España entre dos siglos (18751931). Continuidad y cambio, Madrid, Siglo XXI, 1991, pp. 3-22.

35 Los cálculos se han hecho sobre los datos de Anuario (1904), op. cit., pp. 218-219; en ese año, las diez Universidades contaban con todas las Facultades, salvo Oviedo (carecía de Filosofía y Letras, Medicina y Farmacia), y Salamanca, Sevilla, Valencia, Valladolid y Zaragoza (a las que faltaba Farmacia).

36 Memoria del Claustro de la Facultad de Ciencias ("Principales datos que deben tenerse presentes para la construcción de un edificio destinado a Facultad de Ciencias y Museo de Ciencias naturales»), en Luis Alfredo Baratas Díaz: "El núcleo de Instituciones científicas matritenses en el Paseo del Prado desde el siglo XVIII", Asclepio, $\mathrm{n}^{\circ}$ 48, (1996), p. 197.

37 Fernando Araujo y Gómez: La Universidad y la Escuela. Organización comparada de las Instituciones universitarias y estadística comparada de la Instrucción primaria en todos los países cultos, Madrid, 1903, p. 6; el autor era, además de catedrático del Cisneros, jefe de la sección de Estadística del Ministerio de Instrucción.

38 La prensa madrileña, y el Parlamento en muchas ocasiones, se hicieron eco de los disturbios estudiantiles en los que se mezclaban alumnos de la Central y de los institutos; para los de diciembre de 1900, Melchor de Almagro San Martín: Biografía del 1900, Madrid, Revista de Occidente, 1943, pp. 264-265, en pp. 47 ss. referencias a los profesores de Derecho.

39 Ana Olivera Poll, La enseñanza en Madrid. Análisis de una Función Urbana, Madrid, Instituto de Estudios Madrileños, 1978, p. 251.

40 Universidad Central de España: Memoria del curso de 1901 a 1902 y Anuario del de 1902 a 1903 de su distrito universitario, Madrid, Imp. colonial, 1903, pp. 38 ss (lista nominal de los alumnos que han recibido el grado de licenciado; entre otros, figura en Filosofía y Letras con el $\mathrm{n}^{0} 14$-de un total de 26- don José Ortega y Gasset), y pp. 48 ss (lista nominal de los alumnos que han recibido el grado de doctor).

41 Conde de Romanones: Notas de Una Vida (1868-1901), t. I, Madrid, Renacimiento, s.a. ( $2^{\text {a }}$ ed.), p. 24; pp. 23 y 31 ss referencias a profesores de Derecho de la Central.

42 La relación nominal de catedráticos que aparece en la Guía (publicada en 1900) parece haberse preparado en los inicios del curso escolar, es decir, en octubre de 1899; así se explica que aparezcan en la misma catedráticos que fallecieron antes de terminar el curso, como Andrés del Busto, Francisco de la Pisa, o Augusto Comas.

43 Universidad Central de España: Memoria..., op. cit., pp. 68 ss. Sorprende en la organización docente de aquella Universidad que hubiera muchos más catedráticos que auxiliares y ayudantes.

44 Diario de Sesiones del Congreso de los Diputados, (sesión de 13 de mayo de 1918), legislatura 1918, tomo III, Madrid, Imp. "Gráfica Excelsior», 1918, p. 1019.

45 Los datos se han sacado sobre todo de publicaciones (biográficas, de historia de la ciencia y de la educación), de la Guía..., de 1900 (y las de 1898, 1899, 1901, y 1902), y del padrón municipal de 1900 (en el que se ha localizado a algo más de la mitad de aquella plantilla). 


\section{Madrid 1900. La capital del sistema educativo}

46 Por ejemplo, Augusto Comas Arques (1834-1900) cobró en 1881-1882 un total de 25.124 pesetas (5.500 como catedrático de ascenso en Madrid, 11.909 de renta de tres casas en Madrid, y 7.715 de ingresos de su bufete); datos del Archivo del Senado que me ha facilitado, y se lo agradezco, S. José Gutiérrez Álvarez.

47 Los entrecomillados proceden de Ramón y Cajal, op. cit., p. 132; el autor se refiere a su propia instalación, modesta, en Madrid en 1892 (pagaba de alquiler 80 pesetas al mes).

48 Fernando Araujo, op. cit., p. 9. 